\title{
МЕЖДУНАРОДНОЕ НАЛОГОВОЕ ПРАВО
}

Голев А. В.

\section{АКТУААЬНЫЕ ВОПРОСЫ РЕФОРМИРОВАНИЯ БЮАЖЕТНОЙ ПОАИТИКИ ЕВРОСОЮЗА}

\begin{abstract}
Аннотачия. Автор подробно рассматривает основные аспекты реформирования бюджетной помитики Евросоюза, в процессе которого столкнулись интересы трех больщих групп стран-участнич ЕС. Показаны внутренние противоречия и различные экономические условия в странах-участницах ЕС, которые с существующей возможностью использовать право вето, делают достижение компромисса в вопросах формирования долговременного бюджета особенно в условиях геополитической и геоэкономической нестабильности весьма хрупким. Автор рассматривает введенные в действие ЕС новые показатели дифференцирования территорий, нуждающихся в субсидиях, по уровню соииально-экономического развития. Автор проводит сравнительный анализ и дает критическую оченку, принятому в результате длительных согласований пятому в истории Евросоюза семилетнему бюджету. В статье отмечается, что в финансовом плане Евросоюза на период с 2014 по 2020 год поддерживается устойчивая тенденция сокращения бюджетных расходов на аграрные и природоохранные программы. Автор подчеркивает, что принят новый налог, который пока что предлагается вводить только в готовых к этому странах ЕС, и он будет взиматься только с финансовых структур - банков, инвестиционных фондов и страховых компаний.
\end{abstract}

Кнючевье слова: бюджет ЕС, Евростат, Европейский фонд, экономика Евросоюза, право вето, социально-экономическое развитие, субсидии, Anпиаl Growth Survey, Европейскал Комиссия, Европарламент.

Review. The author of the article examines the main aspects of the reform of the budgetary policy in the European Union, during which the interests of epy three large groups of EU Member States collided. In his 


\section{МЕЖАУНАРОАНОЕ НААОГОВОЕ ПРАВО}

research Golev shows the internal contradictions and different economic conditions in the EU Member States, which, considering their possibility to use the veto right, make it very difficult to reach a compromise regarding the formation of the long-term budget particularly considering the current geopolitical and geo-economical instability. The author considers the EU new measures differentiating areas in need of subsidies depending on their levels of socio-economic development. The author carries out a comparative analysis and critical assessment, adopted after lengthy approvals of the fifth seven-year EU budget. The author of the article notes that in the financial terms of the European Union, for the period from 2014 to 2020 the UE maintains a steady trend of budget cuts on agricultural and environmental programs. The author emphasizes the adoption of the new tax, which is so far offered to be implemented only in the EU countries that are ready for that, and it will be charged only from financial institutions - banks, investment funds and insurance companies.

Keyworlds: European Parliament, Annual Growth Survey, EU budget, European Commission, subsidies, socio-economic development, economy of the European Union, veto, European Fund, Eurostat.

$\mathrm{E}$ щё в ноябре 2013 года Европарламентом был утвержАен проект финансового пла-

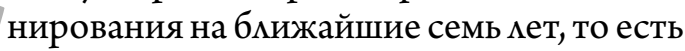
на периоА с 2014 по 2020 гоА. Этот бюАжетный план быи принят после Аолгих Аискуссий, поскольку право ветирования бюАжета Аюбым из 28-и участников вынужАало к поиску болезненных компромиссов. В Аанном документе столкнулись интересы трех больших групп странучастниц ЕС: стран северной Европы с сильной экономикой (Вемикобритания, Нидерланды и Швеция), которые настаивали на сокращении расходов бюджета. Они к тому же отстаивали традиционные скидки с национальных взносов этих стран в общий бюАжет. Наиболее жесткого курса придерживались представители Великобритании, поскольку ее премьер-министр АэвиА Кэмерон находился поА сильным Аавлением у себя в стране, поэтому в вопросе британской скиАки он был не готов иАти на уступки. Так же и Франция требовала сохранить субсидии Аля собственного сельского хозяйства, играющего в ее экономике значительную роль.

В то же время страны южной и восточной Европы со слабой экономикой стремились оставить за собой традиционные дотации Евросоюза, преАназначенные Аля развития отстающих регионов. Аругие участники оказались втянуты в конфликт интересов, например, в Германии оАни политики (например, Канциер Ангела Меркель) выступают за режим жесткой бюАжетной экономии, а Аругие политики (например, министр сельского хозяйства ФРГ Ильзе Айгнер) требуют сохранить европейские субсидии Аля фермерских хозяйств. При этом все страныучастники ЕС нацемены на получение скидок на свои взносы в европейский бюАжет.
Все эти внутренние противоречия и размичные экономические условия в странахучастницах EC, а так же упомянутое право вето, делало достижение компромисса очень хрупким. Руководство Европейской Комиссии пошио по пути частичного удовлетворения всех требований, опираясь на сокращение «неприоритетных» статей бюАжета.

Быми сокращены такие статьи расходов, как финансирование образования, научных разработок, межгосударственных инфраструктурных проектов, то есть по факту именно те направления, которые могми бы способствовать толчку к интенсификации европейской экономики, которая уже пять мет находимась к этому моменту в затяжном финансовом и производственном кризисе, последовавшем за обвалом 2008 года.

Принятый в результате Алительных согласований семилетний бюАжет был по счету пятым в истории Евросоюза. Первый общий бюАжет был принят в 1988 году (на базе так называемого Пакета Аелора-І был принят пятикетний финансовый план Сообщества на 1988-1992 гг.), второй - охватывац периоА с 1993 по 1999 годы, третий - 2000-2006 гг., посмеАний бюАЖет ЕС быи утвержден на 2007-2013 годы. Необходимо отметить, что в ЕС используются Ава виАа бюджетного планирования: среАнесрочное и ежегодное. Среанесрочный бюАжет фиксирует предельно Аопустимые показатели расходов европейского объединения, которые потом соответственно транслируются в годовые планы, реализуя таким образом экономическую стратегию Евросоюза.

Основные параметры Аействующего бюАжетного плана еАиной Европы таковы: предель- 


\section{НА ОГИ И НААОГООБАОЖЕНИЕ • $12(138) \cdot 2015$}

ный размер - 960 млрА. евро; снижение мимита бюджетных расходов на 3,4\% по сравнению с периодом 2007-2013 гг.; сокращение взноса от стран-участниц с 1,06\% совокупного валового национального дохода ЕC, как было зафиксировано в преАыАущем бюАжетном периоде, Ао 0,95\%, что эквивалентно 908 мирА. евро [1], [2]. При этом ЕС ввем в Аействие новые показатели Аля того, чтобы Аифференцировать территории, нужАающиеся в субсиАиях, по уровню социально-экономического развития. Показатель уровня валового регионального продукта на Аушу населения остался без изменений, как решающий фактор, определяющий необходимость оказания финансовой помощи нужАающимся регионам, но были изменены их пороговые величины, определяющие размеры необходимых субсидий. Принята практика Аифференциации на три группы: слабо развитые (те, где уровень валового регионацьного продукта на Аушу населения менее $75 \%$ от среАнего по Евросоюзу), промежуточные (уровень вацового регионацьного продукта в Аиапазоне от 75 Ао 90\%) и хорошо развитые (уровень вамового регионацьного продукта выше 90\% от среАнего по ЕС). При разработке нового семиметнего финансового пиана особое место Аолжно было уАеляться повышению конкурентоспособности Еврозоны и созАанию новых рабочих мест. И если в преАыдущем периоде на эти цели было направлено 9,2\% всех бюджетных расхоАов, то в нынешнем периоде эта статья увеличена до $13,1 \%$ (125,6 мира. евро).

Зашкаливающий уровень безработицы в Евросоюзе (в 2013 году уровень безработицы в ЕС бым 12,3\%, в первом квартаме 2015 он снизился Ао 11,3\%, при этом в Испании он Аостигает 23,0\%, в Португамии $23,0 \%$, а в Итамии $13,0 \%$ ) [3] вынуаим Евросоюз повысить расхоАы на создание новых рабочих мест. Эта программа будет финансироваться посредством таких организаций, как Европейский социамьный фонА и Европейский фона регионамьного развития. Поскольку уровень безработицы среАи молодежи еще выше, то решено было инвестировать 6 ммрА. евро (из них 2,1 мирА. - в 2014-2015 гг.) в программу «Инициативы молодежной занятости», чтобы способствовать в устройстве на работу молодежи в возрасте Ао 25 мет из слаборазвитых регионов Евросоюза. Так же на поААержку образования Аля европейской момоАежи АО 15 мирА. евро (на 40\% по сравнению с преАЫаущим среАне- срочным планом) увеличен бюджет программы «Эразмус+».

Надо сказать, что увекичение финансирования по этим направлениям вызывало большую Аискуссию, поскольку некоторые преАставители высказывали точку зрения, что эффективность многих структурных проектов в слабо развитых регионах невелика. СубсиАии, на протяжении нескольких мет интенсивно поступавшие в Грецию, Испанию, Португалию, так и не смогми оказать ощутимое воздействие на инфраструктуру этих стран. Так же вызывали возражения огромные субсиАии аграрному сектору в резумьтате основной упор бым сАелан на поААержку малого и среАнего бизнеса, к которому относится более $90 \%$ европейский фирм, и в котором Аействует почти треть рабочих мест в частном секторе. С 2014 по 2020 гг. объем финансирования цемевых проектов по оказанию содействия мамому и среАнему бизнесу через Европейский фонА регионакьного развития увекичится с 70 ао 140 мира. евро.

Программа научно-исследовательских и инновационных работ «Горизонт- $2020 \gg$ помучима из бюАжета 80 млрА. евро, что на треть больше, чем была профинансирована анамогичная программа 2007-2013 годов. Эти вможения Аолжны способствовать повышению конкурентоспособности ЕС, поскольку цемью программы является обеспечение рабочего взаимодействия межАу образоватемьными учрежАениями, наукой и бизнес-средой, а так же подАержка start-up-компаний и специального ПостАИПломного образования. ОтАельное внимание УАемяется межАународному сотруАничеству в сфере инноваций и высоких технологий. Расходы бюАжета ЕС на программы по поААержке развития собственной структуры («ГАобальная Европа», «Безопасность и гражАанство»), а так же расходы аАминистративного характера по сравнению с преАылущим периодом практически не возросли, а если и увеличимись, то незначительно (в преАелах 2\%). В финансовом плане Евросоюза на периоА с 2014 по 2020 гоА поААерживается тенденция сокращения бюАжетных расходов на аграрные и природоохранные программы, хотя бюАжет программы «Устойчивое развитие: природные ресурсы» и составляет 40,2\% всех расходов ЕС текущего семиметнего периоАа, но по сравнению с прошиой программой он сократился на 9,5\% [4]. 


\section{МЕЖАУНАРОАНОЕ НАЯОГОВОЕ ПРАВО}

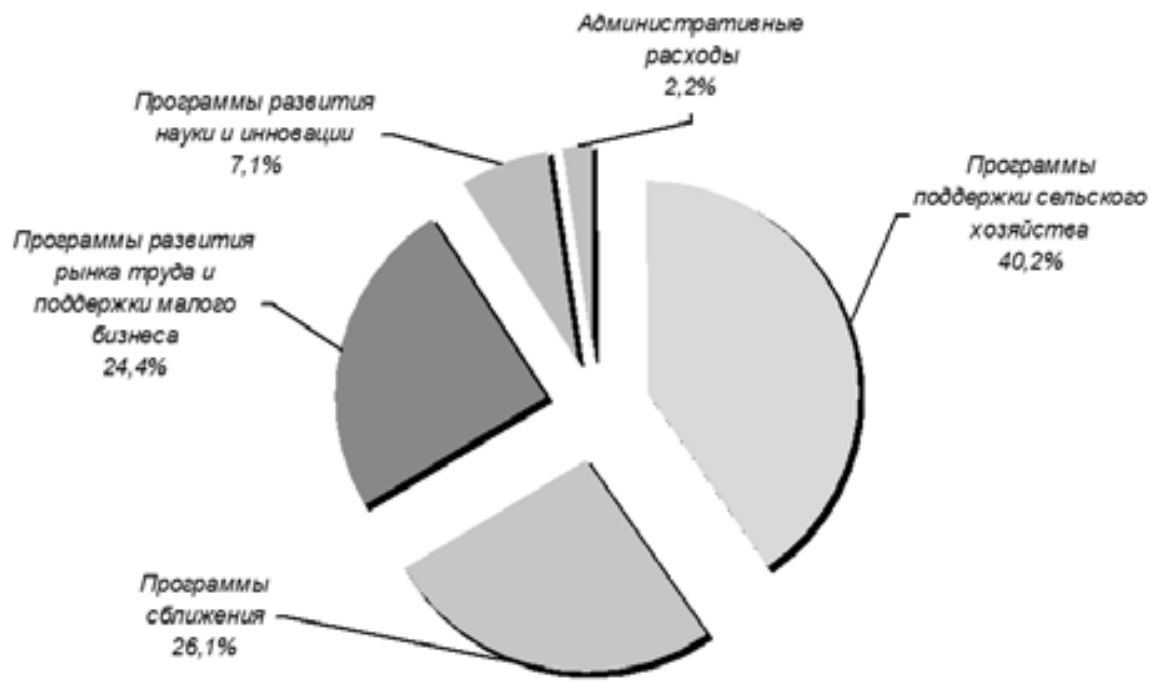

Рисунок 1. Структура расходов бюджетного плана ЕС 2014-2020

(Источник: составлено автором на основе данных Eurostat)

Но основная сложность формирования нового семилетнего бюджетного плана ЕС была связана не столько с утверждением расходных статей, сколько с решением вопроса о пополнении его Аоходной части. Аоходную часть бюАжета составляют так называемые «собственные среАства ЕС», состоящие из:

1. обычных собственных среаств (составмяющих около 14\% бюАжета Евросоюза), со- мяющих собой производное от их валового национального дохода (ВНА), характеризующие экономический результат страны в текущем году;

4. прочих Аоходов - 2,5\%, преАставляющих собой налоги на Аоходы чиновников ЕС, АохоАов от ставок по банковским вкладам, взносов от стран, не входящих в ЕС, возврата неиспользованных среАств, штрафов юридических миц за нарушение законодательства Евросоюза и т. п.

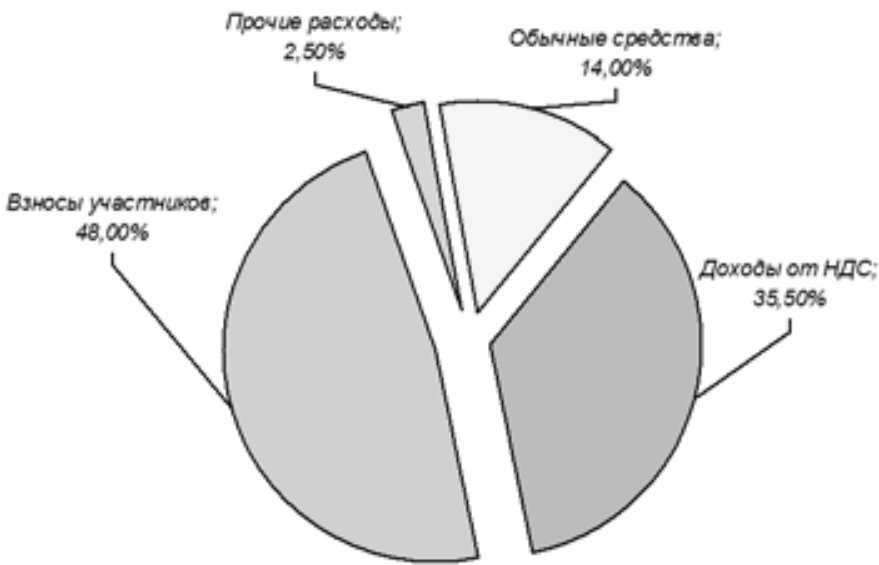

Рисунок 2. Структура доходов бюджетного плана ЕС 2014-2020

(Источник: составлено автором на основе данных Eurostat)

стоящих из таможенные и прочих платежей, взимаемых при импорте товаров из стран, не явмяющихся участниками ЕС;

2. Аоходов от налога на добавленную стоимость НАС (составмяют около $35,5 \%$ в АохоАах бюджета) в форме его установменной части $(0,3 \%)$ от «базы исчисмения НАС», оАинаковой Аля всех стран-участниц базы налога;

3. взносов участников (наибольшей части Аоходов бюАжета ЕС - 48\% в бюАжете), преАстав-
Подготовка первоначального проекта семиметнего финансового плана на 2014-2020 годы вызвала в Еврокомиссии дискуссию, связанную с планами по изменению системы налоговых отчислений в общий бюАжет. Высказывалось предложение по реформе существующей системы собственных средств ЕС, связанных с отчисмениями от НАС, поскольку она очень сложна в аАминистрировании. Отказ от нее может позволить уменьшить административные расходы 


\section{НА ОГИ И НААОГООБАОЖЕНИЕ • 12 (138) • 2015}

на национальном и наднациональном уровнях. Предполагается, что реформа системы произойдет Ао начала 2018 года. За это время существующие сейчас отчисления в общий бюАжет от НАС Аолжны быть замещены новой системой отчислений от налога на Аобавленную стоимость и сборами от нового налога на финансовые трансакции в размере $0,1 \%$ (по операциям обмена акциями и облигациями) и $0,01 \%$ (по операциям с вторичными контрактами). Этот новый налог, который пока что преАлагается вводить только в готовых к этому странах ЕС, будет взиматься только с финансовых структур - банков, инвестиционных фондов, страховых компаний и т. А.

Аля проведения реформы источников бюджетных Аоходов в Евросоюзе была создана специальная структура (Рабочая группа высокого уровня), возглавляемая бывшим премьером Италии Марио Монти и состоящая из преАставителей Европейской комиссии, Европарламента и Совета Европы [5]. На заседании, состоявшемся в феврале этого года, Марио Монти преАставил первые очень осторожные выводы о реформе собственных доходов бюджета ЕС. Он анонсирует относительные изменения, а не кардинальное преобразование системы, поскольку это может вызвать конфмикт интересов. Основным недостатком бюджета ЕС явмяется отсутствие у него автономии, то есть собственных прямых доходов. В самом Аеле, значительная часть Аоходов бюджета ЕС формируется не за счет собственных ресурсов, а из взносов государств-чкенов, рассчитанных в соответствии с их экономическим весом, подмежащих различным исключения и оговоркам, таким, например, как «Британские скиАки». Это вынуждает АваАцать восемь участников жестоко торговаться в ходе обсужАения их участия в европейском бюАжете. «Примерно 83\% бюАжетных ресурсов 2014 года пришли из прямых взносов из национальных бюАжетов. Эта ситуация сАелана переговоров по бюАжету еще более резкими, - отметил Марио Монти в ходе своего доклада [6].

При этом главные разногласия межАу парцаментом и советом ЕС по поводу формирования бюАжета, объясняются стремлением более развитых стран Европы продолжать воздействовать на менее развитые страны Европы с целью усиления их финансовой Аисциплины. Поэтому в бюАжете планируется относительно низкий рост расходов, что свидетельствует о Аальнейшей фискальной консолидации, которая уже Аает себя знать, так как бюАжетные дефици- ты проблемных стран сократились в среднем с $24 \%$ в 2011 году до 11\% в 2014, согласно Annual Growth Survey [7], [8].

Это свидетельствует о том, что намечается некоторое финансовое оздоровление, которое Аолжно способствовать восстановлению доверия к устойчивости национальных финансовых институтов и развитию стабилизации финансовой ситуации в некоторых странах Евросоюза и всего интеграционного объединения в целом.

Хотя в отдельных странах до сих пор сохраняются определенные риски в отношении соблюдения бюджетных параметров. Это относится к Бельгии, Италии и Франции, которые настаивают на своем праве выйти за рамки преАписанных Европейской Комиссией бюджетных расходов, ради придания импульса своим стагнирующим экономикам. В настоящее время эти государства проводят ряА структурных реформ (реформу рынка труаа, реформу образования, реформы пенсионной системы и т. А.). ОжиАается, что эти реформы позволят поднять рост экономики в этих странах и стабилизировать их финансовое состояние в среАнесрочной перспективе.

Как эффективные Еврокомиссия рассматривает реформы, проведенные в Польше и Португалии, которые привели к значительному снижению уровня безработицы в этих странах. Например, в Польше успешно прошиа реформа рынка труда, облегчившая Аоступ ко многим регулируемым профессиям. В Италии в 2013 году были преАприняты меры по повышению конкуренции в энергетическом секторе экономики, что помогло решению острой проблемы высокой стоимости энергоносителей в Италии и Аало возможность снизить цены на энергию ААя конечных потребителей.

Все это способствует озАоровлению экономики Евросоюза, что в свою очереАь позволяет снижать конфронтационные риски при формировании бюджетного плана союза. ОАнако главным препятствием к реформированию бюАжетной системы остаются гмубокие разногласия заинтересованных сторон. «Мы Аолжны оценить наши возможности, может ми реформа быть успешной или потерпит неудачу,» - признался Марио Монти. «Позиции в группе не явцяются оАнородными, и мы не сможем избежать этой конкуренции интересов,» - подытожиц глава рабочей группы [9].

Итальянский преАставитель указал, что желательны корректировки, а не радикальные 


\section{МЕЖАУНАРОАНОЕ НААОГОВОЕ ПРАВО}

моАификации, это сАелает реформу более вероятной. В частности, преАложено обуздать пар-

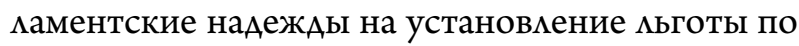
налогу на финансовые операции или налогу на выбросы углерода, что может пополнить бюАжет ЕС. При этом всем участникам понятно, что без решения вопроса Аоходов бюАжета ЕС меАленно и неумолимо умрет [10] Проблема не нова. С 2006 года Европарламент пытается провести реформу Аоходов бюАжета ЕС. Бурные Аебаты по формированию многометнего бюАжета ЕC на период 2014-2020 годов вызвали Ааже созАание вышеупомянутой Рабочей группы высокого уровня, а накопление неоплаченных счетов бюАжета ЕС подтверждает актуальность проблемы.

Группа экспертов Аает осторожную преАварительную оценку возможности успешной реализации нововвеАений, что объясняется трудностью ратификации мюбой реформы по налоговым вопросам, поскольку мюбое изменение в правилах бюАжетного финансирования ЕС требует еАиногласного голосования Совета. Правимо требует при проведении реформ стремиться к Аостижению консенсуса и отказаться от раАикамьных изменения, чтобы не отпугнуть госуАарств-участников.

Аругие кмючевые партнеры в этой огромной реформе - национацьные парламенты, которые также Аомжны ратифицировать мюбые изменения правия бюАжетного финансирования.
«Нам надо Аействовать творчески, амбициозно, но осторожно, чтобы не увеличивать налоговую нагрузку наших гражАан. КажАый евро, собранный на уровне ЕС, Аомжен уменьшить налоговую нагрузку на национахьном уровне. Наконец, нам немьзя Аушить конкурентоспособности Европы, подавмяя производство и заработную пиату и порожАая, таким образом, перенос производства в Аругие регионы мира», - сказал Жан Arthuis (ALDE, Франция), председатель Комитета по бюАжету [11].

Работу наА реформой бюАжетной системы преАполагается вести в Ава этапа. Первый этап будет посвящен выработке принципов, позволяющих вернуться к исходной системе финансирования бюАжета ЕС путем его прямого пополнения. На втором этапе Аолжны быть преАложены инструменты, которые позволят выбрать источники Аля Аостижения этой цели, а так же опреАелены необходимого размера этих собственных среАств. Окончить свою работу Группа высокого уровня по вопросу собственных ресурсов бюАжета Аля предоставления пиана Европейской комиссии преАполагает в 2016 году. Вместе с тем на 2016 год назначена и процедура, направленная на ревизию бюджетных параметров, связанная с потенциацьными изменениями экономической ситуации в Евросоюзе, а значит, не исключается отхоА от формируемого с таким труАом бюАжетного плана ЕС на 2014-2020 годы.

\section{БИБАИОГРАФИЯ}

1. European Commission-Budget. Financial framework 2007-2013 (Аанные Европейской комиссии по многолетним бюАжетным планам на 2007-2013 гг. и на 2014-2020 гг.) URL: http://ec.europa. eu/budget/figures/fin_fwk0713/fwk0713_en.cfm\#cf07_13.

2. European Commission-Budget. Multiannual Financial Framework. URL: http://ec.europa.eu/ budget/mff/figures/index_en.cfm.

3. Eurostat. URL: http://ec.europa.eu/eurostat/tgm/table.do?tab=table\&language =en\&pcode=teilm0 20\&tableSelection $=1$ \&plugin $=1$.

4. Communication from the Commission to the European Parliament, the Council, the European economic and social committee and the committee of the regions. A Budget for Europe 2020. URL: http://ec.europa.eu/budget/library/biblio/documents/fin_fwk1420/ MFF_COM-2011-500_Part_I_en.pdf.

5. Financial framework proposed by the European Commission. URL: http://ec.europa.eu/budget/ $\mathrm{mff} /$ figures/index_en.cfm\#commissionproposal.

6. Réforme du budget européen: «mission impossible»? URL:-http://www.euractiv.fr/sections/ euro-finances/reforme-du-budget-europeen-mission-impossible-311885.

7. Report on the European Semester for economic policy coordination: Annual Growth Survey 2014. URL: http://ec.europa.eu/europe2020/pdf/2014/ags2014_en.pdf.

8. Коромева А. Компромиссный бюАжет // URL:-http://expert.ru/2014/12/1/ kompromissnyij-byudzhet/.

9. Мировая экономика: прогноз до 2020. Под реА. акаА. А.А. Аынкина / ИМЭМО РАН. - М.: Магистр, 2007. - 429 с. 


\section{НА ОГИ И НААОГООБАОЖЕНИЕ • 12 (138) • 2015}

10. Колодко Г. В. ГАобализация, трансформация, кризис - что Аальше? Вводная глава Р. С. Гринберга. - М.: Магистр, 2011. - 176 с.

11. European Council Conclusions (Multiannual Financial Framework), EUCO 37/13, Brussels, 8 February 2013. URL: http://www.consilium.europa.eu/uedocs/cms data/docs/pressdata/en/ ec/135344.pdf.

12. Знаменский А.Ю. К вопросу о применении системно-динамического поАхода к исследованию процессов формирования и реализации государственной научно-технической политики // Социодинамика. - 2014. - 7. - C. 50 - 63. DOI: 10.7256/2409-7144.2014.7.12801. URL: http:// www.e-notabene.ru/pr/article_12801.html.

13. Покачалова Е.В. Правовые проблемы публичного Аолга в условиях дефицитной и профицитной бюАжетной политики государства // Финансовое право и управление. - 2014. - 1. - С. 4 - 22. DOI: $10.7256 / 2310-0508.2014 .1 .9890$.

14. А. И. Некрасов Принципы правового регулирования политики Европейского Союзав области финансовых ускуг // МежАународное право и международные организации / International Law and International Organizations. - 2011. - 3. - C. $69-87$.

\section{REFERENCES}

1. European Commission-Budget. Financial framework 2007-2013 (Dannye Evropeiskoi komissii po mnogoletnim byudzhetnym planam na 2007-2013 gg. i na 2014-2020 gg.) URL: http://ec.europa.eu/ budget/figures/fin_fwk0713/fwk0713_en.cfm\#cf07_13.

2. European Commission-Budget. Multiannual Financial Framework. URL: http://ec.europa.eu/ budget/mff/figures/index_en.cfm.

3. Eurostat. URL: http://ec.europa.eu/eurostat/tgm/table.do?tab=table\&language $=$ en $\& p c o d e=t e i l m 0$ 20\&tableSelection $=1 \&$ plugin $=1$.

4. Communication from the Commission to the European Parliament, the Council, the European economic and social committee and the committee of the regions. A Budget for Europe 2020. URL: http://ec.europa.eu/budget/library/biblio/documents/fin_fwk1420/ MFF_COM-2011-500_Part_I_en.pdf.

5. Financial framework proposed by the European Commission. URL: http://ec.europa.eu/budget/ $\mathrm{mff} /$ figures/index_en.cfm\#commissionproposal.

6. Réforme du budget européen: «mission impossible»? URL:-http://www.euractiv.fr/sections/ euro-finances/reforme-du-budget-europeen-mission-impossible-311885.

7. Report on the European Semester for economic policy coordination: Annual Growth Survey 2014. URL: http://ec.europa.eu/europe2020/pdf/2014/ags2014_en.pdf.

8. Koroleva A. Kompromissnyi byudzhet // URL:-http://expert.ru/2014/12/1/ kompromissnyij-byudzhet/.

9. Mirovaya ekonomika: prognoz do 2020. Pod red. akad. A.A. Dynkina / IMEMO RAN. - M.: Magistr, 2007. - $429 \mathrm{~s}$.

10. Kolodko G. V. Globalizatsiya, transformatsiya, krizis - chto dal'she? Vvodnaya glava R.S. Grinberga. M.: Magistr, 2011. - $176 \mathrm{~s}$.

11. European Council Conclusions (Multiannual Financial Framework), EUCO 37/13, Brussels, 8 February 2013. URL: http://www.consilium.europa.eu/uedocs/cms_data/docs/pressdata/en/ ec/135344.pdf.

12. Znamenskii D. Yu. K voprosu o primenenii sistemno-dinamicheskogo podkhoda $\mathrm{k}$ issledovaniyu protsessov formirovaniya i realizatsii gosudarstvennoi nauchno-tekhnicheskoi politiki // Sotsiodinamika. - 2014. - 7. - C. 50 - 63. DOI: 10.7256/2409-7144.2014.7.12801. URL: http:// www.e-notabene.ru/pr/article_12801.html.

13. Pokachalova E.V. Pravovye problemy publichnogo dolga $\mathrm{v}$ usloviyakh defitsitnoi i profitsitnoi byudzhetnoi politiki gosudarstva // Finansovoe pravo i upravlenie. - 2014. - 1. - C. 4 - 22. DOI: 10.7256/2310-0508.2014.1.9890.

14. A. I. Nekrasov Printsipy pravovogo regulirovaniya politiki Evropeiskogo Soyuzav oblasti finansovykh uslug / / Mezhdunarodnoe pravo i mezhdunarodnye organizatsii / International Law and International Organizations. -2011 . - 3. - C. $69-87$. 